\title{
Water Absorption Study in Recycled Aggregates for Use as Pavement Material
}

\author{
Vahid Ayan ${ }^{*}$, Joshua R. Omer², Seyed Masoud Nasr Azadani' ${ }^{3}$ Mukesh C. Limbachiya², \\ Alireza Khavandi 4 \\ ${ }^{1}$ Department of Civil Engineering, Islamic Azad University (IAU), Islamshahr Branch, Tehran, Iran \\ ${ }^{2}$ Sustainable Technology Research Center, Kingston University London, London, UK \\ ${ }^{3}$ Department of Railway Engineering, Iran University of Science \& Technology, Tehran, Iran \\ ${ }^{4}$ Department of Civil Engineering, Faculty of Engineering, University of Zanjan, Zanjan, Iran \\ Email: vahidayan@iiau.ac.ir, j.r.omer@kingston.ac.uk, Azadani@iust.ac.ir, m.limbachiya@kingston.ac.uk, \\ akhavandi@iust.ac.ir
}

Received 4 June 2014; revised 15 July 2014; accepted 25 August 2014

Copyright (C) 2014 by authors and OALib.

This work is licensed under the Creative Commons Attribution International License (CC BY). http://creativecommons.org/licenses/by/4.0/

(c) (i) Open Access

\begin{abstract}
Water absorption properties of recycled materials play an important role in pavement performance. The performance of aggregates changes after absorbing water, then it affects highways layers such as base, subbase, capping. This is why these materials must comply requirements of codes and standards. With regard to the increasing trend of application of recycled aggregates in highways layers, this issue needs more investigation. This research is only a part of our large research programme on three different purposed mixes of unbound subbase mixture below: 1) 100\% Recycled Concrete Aggregate (RCA); 2) 100\% Lime Stone (NA); 3) 50\% RCA + 50\% Reclaimed Asphalt Pavement (RAP). Water absorption for each mix has been performed in different size fraction with pyknometer and wire basket methods. The relation ship between density, gra ding and water absorption and its comparison for mixes would be indicating the changes in beha $v$ iour of aggregates and future performance of subbase. Laboratory testing showed that $100 \%$ Lime Stone had the higher densities than other mixes and water absorption value of 100\% RCA was about $40 \%$ higher than $50 \%$ RCA + 50\% RAP in $31.5 \mathrm{~mm}-4 \mathrm{~mm}$ fraction.
\end{abstract}

\section{Keywords}

Water Absorption, Recycled Aggregate, Reclaimed Asphalt Pavement, Density, Subbase

Subject Areas: Civil Engineering, Environmental Sciences

\footnotetext{
*Corresponding author.
}

How to cite this paper: Ayan, V., Omer, J.R., Azadani, S.M.N., Limbachiya, M.C. and Khavandi, A. (2014) Wa ter Absorption Study in Recycled Aggregates for Use as Pave ment Ma terial. Open Access Library Journal, 1: e605. 


\section{Introduction}

During the last two decades, various researches were carried out to investigate the possibility of using construction and demo lition waste. RA and RCA are subjects of debate in so far as application in road bases and subbases are concerned. Evaluation showed that RCA and RA from different sou rces have different mechanical properties based on their origin [1].

In a research by Park (2003), tests were carried out for physical and compaction properties of two different recycled aggregates obtained from a housing redevelopment site (RCA-1) and a concrete pavement rehabilitation project (RCA-2). This research revealed that the bulk specific gravity and water absorption values were $2.53 \%, 2.54 \%, 1.43 \%$ and $1.77 \%$ for RCA-1 and RCA-2, respectively [2]. Elsewhere, physical and mechanical tests were carried out on crushed clay brick (CB) from partition wall and RCA by Poon and Chan (2006). The particle sizes of the RCA were: $40 \mathrm{~mm}, 20 \mathrm{~mm}, 10 \mathrm{~mm}$ and $<5 \mathrm{~mm}$ and the water absorption values were: $3.17 \%$, $2.17 \%, 2.29 \%$ and $10.3 \%$, respectively. The aggregates size of CB was $20 \mathrm{~mm}, 10 \mathrm{~mm}$ and $<5 \mathrm{~mm}$ with water absorption results $18.4 \%, 19.5 \%$ and $30.9 \%$, respectively. It was concluded that $\mathrm{CB}$ had the highe st water absorption value, followed by RCA and natural aggregate. The high amount of adhered mortar attached to the $\mathrm{CB}$ particles led to increase in the water absorption value [3].

Another research was carried out on the utilization of RCA in rigid pavements. A part of this study was the construction of a Portland Cement Concrete Pavement (PCCP) section using RCA and a field study of the performance of the pavement. Based on the results of the tests it was concluded that use of fine RCA is not practical because of its high water absorption rate [4]. Investigations were carried out on 11 RA samples obtained from 10 demolition sites and a recycling plant. The study revealed that in most samples, the water absorption of $10 \mathrm{~mm}$ aggregates was higher than $20 \mathrm{~mm}$ aggregates. It was inferred that smaller size aggregates had more cement mortar which absorbed more water than larger size aggregates. In addition a correlation was found to exist between particle density, porosity and water absorption [5].

Existing regulated tests to determine the density and water absorption were developed for natural aggregates, however, and several problems arise when they are applied to recycled aggregates, especially fine recycled a ggregates. These difficulties mostly are because of their cohesiveness and binding properties. Rodrigues et al. (2013) described the main problems encountered with these tests and proposed a new method to measure the density and water absorption of fine recycled aggregates that removes them. They used sodium hexametaphosphate solutions in the water absorption test to improve its efficiency, minimizing cohesion between particles and helping to release entrained air [6].

The main the me of this research is to compare the water absorption properties of different recycled aggregates and their mixes according to BS EN 1097-6:2000 [7].

\section{Materials}

The research concentrated on investigating the suitability of three kinds of aggregates which all are Type 1 unbound mixture for subbase [8] (Figures 1(a)-(c)):

1) $100 \%$ Recycled Concrete Aggregate (RCA) which is indicated with the notation T-1.

2) $100 \%$ Lime stone as the natural aggregate (NA) which is indicated with the notation T-2.

3) $50 \%$ Recycled Concrete Aggregate (RCA) + 50\% Reclaimed Asphalt Pavement (RAP) which is indicated with the notation $\mathrm{T}-3$.

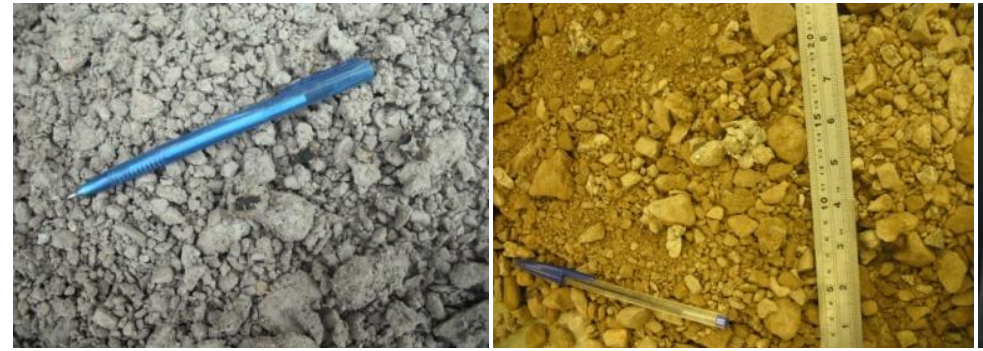

(a) (b)

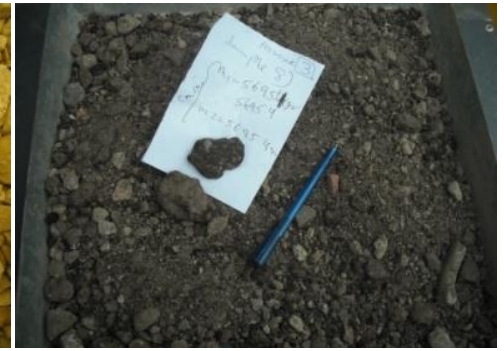

(c)

Figure 1. (a): A sample of T-1; (b): A sample of T-2; (c): A sample of T-3. 
The grading curves of three above aggregates, the upper and the lower range of Type 1 unbound mixtures given according to MCHW Series 800 are illustrated in Figure 2.

For all three kinds of aggregates; the mixture designation is 0/31, 5 (aggregate sizes are expressed as d/D or lower limiting sieve size/upper limiting sieve size), the Maximum fines content is $\mathrm{UF}_{9}$ and Oversize is $\mathrm{OC}_{75}$ which meet the requirements of MCHW Series 800 requirements [8] [9].

\section{Current Specifications}

The determination of water absorption was based on the provisions outlined in the three documents: BS EN 13285:2003, MCHW Series 800 and DMRB HD 35/04 [8]-[10]. Four types of unbound mixtures for subbase application are defined by MCHW Series 800. To determine water absorption rate, BS EN 1097-6 requires that the method selection should be based on the particle size range as outlined below [7]:

Particle size range Method used

$31.5 \mathrm{~mm}-63 \mathrm{~mm} \quad$ Wire-basket method

$4 \mathrm{~mm}-31.5 \mathrm{~mm} \quad$ Pyknometer method

$0.063 \mathrm{~mm}-4 \mathrm{~mm} \quad$ Pyknometer method

Preparation of test portions in both wire-basket and pyknometer methods included sampling and reduction which were performed in accordance with BS EN 932-1 and BS EN 932-2, respectively [11] [12].

Density measurements included: 1$)$ oven-dry particle densities $\left.\left(\rho_{r d}\right) ; 2\right)$ saturated and surface-dry density $\left(\rho_{s s d}\right)$; 3) apparent particle density $\left(\rho_{a}\right)$. The parameter $\rho_{r d}$ is the characteristic used to calculate the volume occupied by the aggregate, for various mixtures of RCA, NA and RAP, respectively. In addition to these solid particles, the voids including permeable and impermeable voids (but not including the voids bet ween particles) must be considered when calculating the masses of aggregates. Interpretation of $\rho_{\text {ssd }}$ is based on aggregates soaked in water for 24 hours to satisfy the water absorption requirement. The weight of aggregates and water within the voids filled during the soaking time (but not including the voids between particles) were calculated to find the mass in air of each mixture. $\left(\rho_{a}\right)$, pertained to the relative density of aggregates not including the permeable pores.

\section{Method Statements}

The method statements for wire-basket and pyknometer method are summarized in Figure 3 and Figure 4, respectively:

In the wire-basket method, the prepared test portion was placed in a wire-basket and immersed in water for a period of 24 hours, so all entrapped air was removed. To dry the surface of saturated aggregates, the test portion transferred to a second dry soft absorbent cloth and was spread and turned until all visible films of water were removed, but the aggregate still had a damp appearance. The oven-dry mass was achieved by placing the test portion in an oven set at a te mperature of $110^{\circ} \mathrm{C} \pm 5^{\circ} \mathrm{C}$ for as long as necessary for the specimen to reach a constant mass.

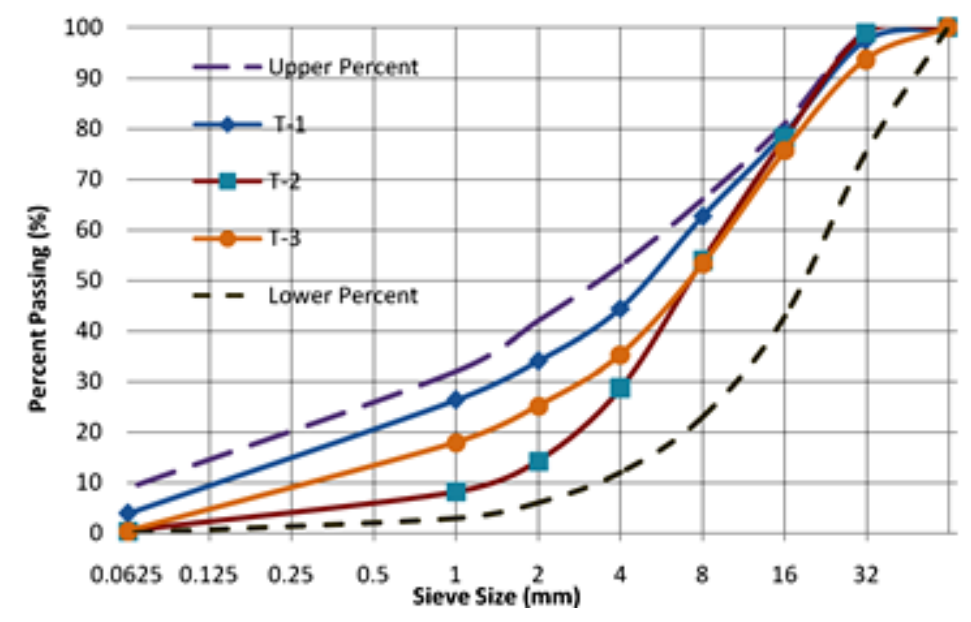

Figure 2. Grading curves for the tested aggregates. 


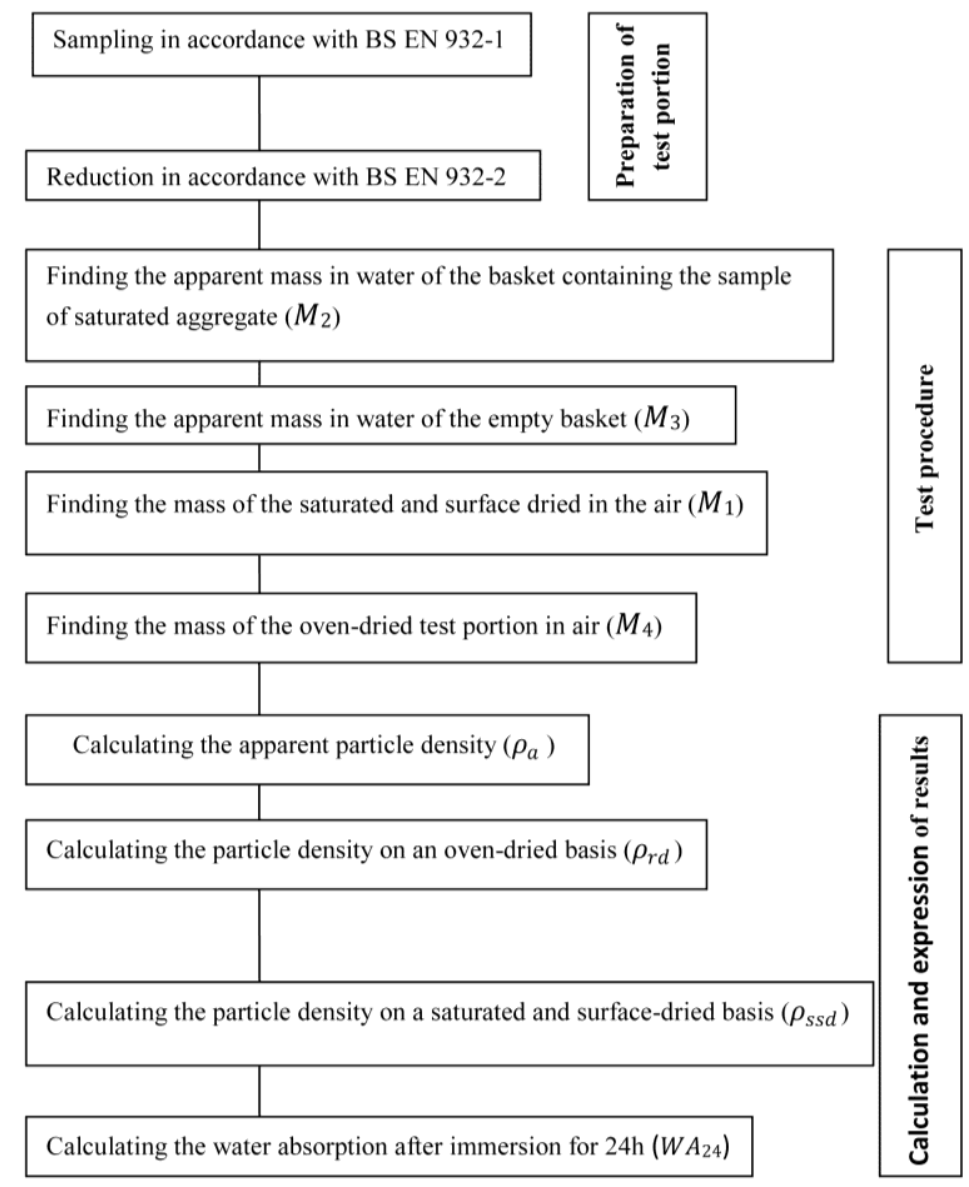

Figure 3. The stages of wire basket method.

In the pykno meter method, the prepared test portion was immersed in water pykno meter for the soaking per iod of 24 hours to remove all entrapped air. According to BS EN 1097-6:2000 the pyknometer including aggregates and water must stand in the water bath and keep the test portion at a temperature of $(22 \pm 3)^{\circ} \mathrm{C}$ for $(24 \pm$ 0.5 ) hours [7]. In this research, to get a higher accuracy, the pykno meter and the refill water was placed in a curing room, which was maintained at a temperature of $20^{\circ} \mathrm{C}$ for 24 hours (Figure 5 and Figure 6). Achieving saturated and surface-dried aggregates for particles size between $4 \mathrm{~mm}$ and $31.5 \mathrm{~mm}$ was exactly the same as aggregate particles size between $31.5 \mathrm{~mm}$ and $63 \mathrm{~mm}$. In order to assess whether the surface dry state has been achieved for aggregate particles between $0.063 \mathrm{~mm}$ and $4 \mathrm{~mm}$, the metal cone mould test was applied.

\section{Test Results and Discussions}

According to mentioned method statements and other require ments of BS EN 1097-6:2000 water absorption test carried out on three kinds of subbase mixtures. The test results for materials of different particle sizes are summarized in Figures 7-10.

The bar charts in Figures 7-10 compare the densities $\left(\rho_{a}, \rho_{r d}, \rho_{s s d}\right)$ and water absorption rates $\left(W A_{24}\right)$ for $24 \mathrm{~h}$ immersion periods. To calculate these densities, the density of water was obtained at the temperature recorded when the apparent mass in water of the basket containing the sample of saturated aggregate $\left(M_{2}\right)$ was determined.

The tests result showed that natural aggregates had the highest apparent particle density $\left(\rho_{a}\right)$, particle density on an oven-dried basis $\left(\rho_{r d}\right)$, particle density on a saturated and surface-dried basis $\left(\rho_{s s d}\right)$ for partic les in all ranges. Conversely, they had the lowest water absorption for particles in all fractions.

As seen in Figures 7-10, for a given kind of density $\left(\rho_{a}, \rho_{r d}, \rho_{s s d}\right)$ the trend of variation of the density with particle size is consistent for all three materials types (T-1, T-2 and T-3). The presence of the cement mortar adher- 


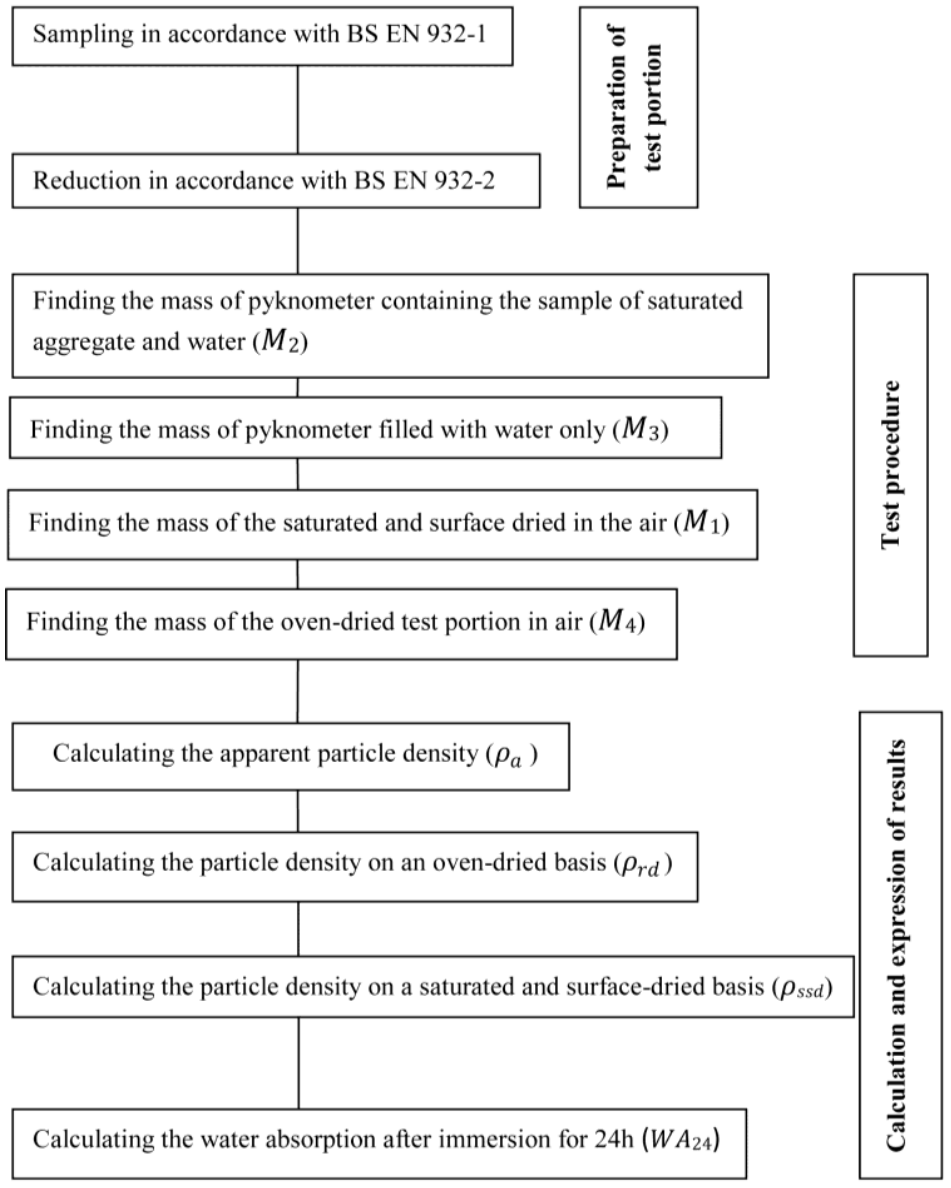

Figure 4. The stages of pyknometer method.

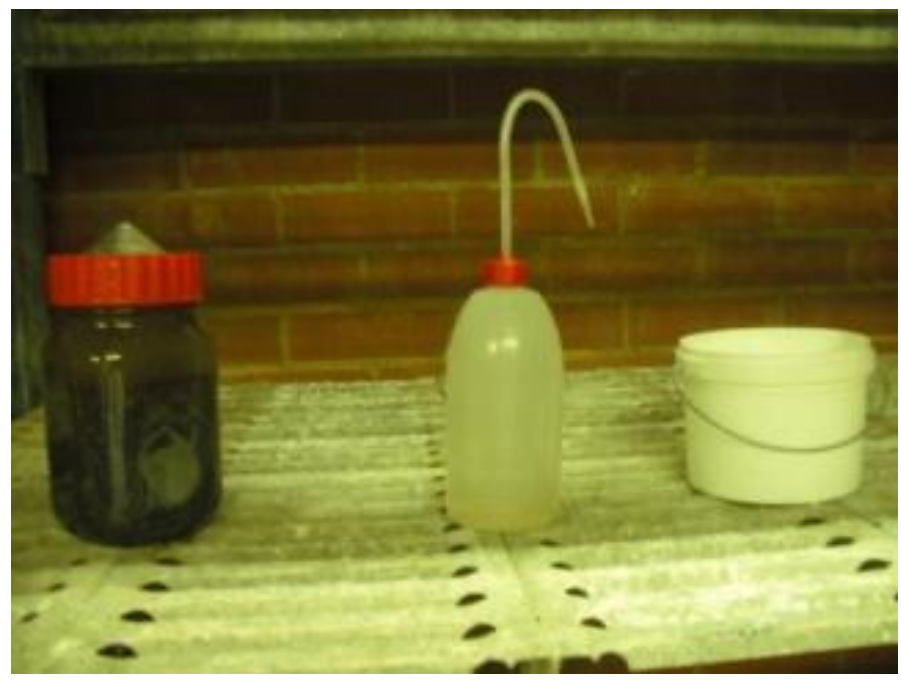

Figure 5. The pyknometer, squeeze bottle and plastic pot in the curing room.

ing to the stone particles in the RCA creates a relatively weak, porous and cracked layer [13] thereby resulting in a decreased density of the RCA relative to NA. It is likely that the porous layer described above, in addition to residual unhydrated cement, lead to an increase in the water absorption rate of RCA [1].

As the density of cement mortar (around $1.0-1.6 \mathrm{Mg} / \mathrm{m}^{3}$ ) [14] is less than that of stone particles of about 2.60 


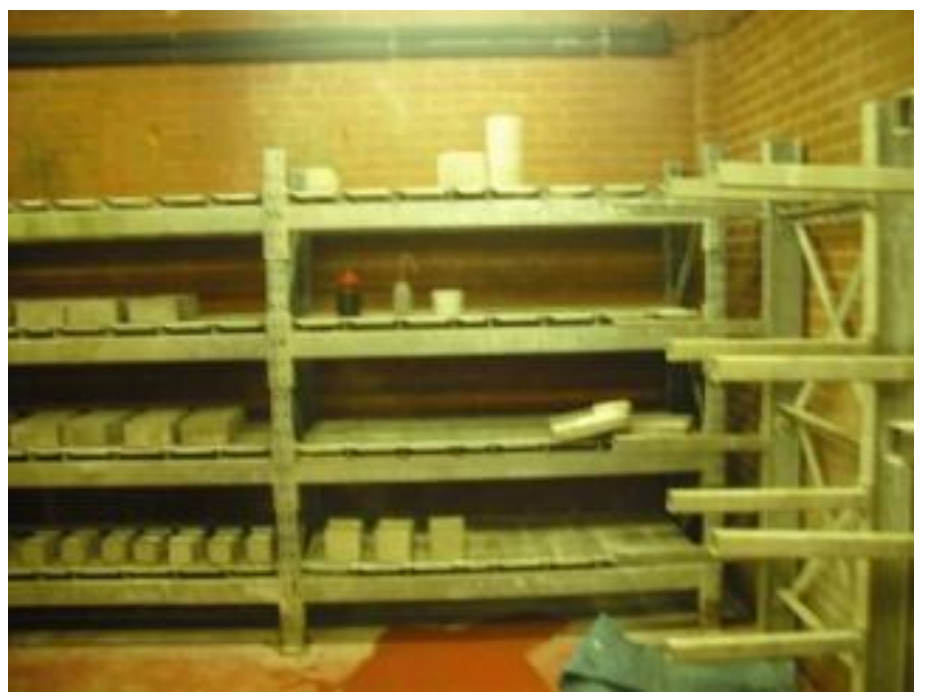

Figure 6. Keeping the temperature of test portion and water constant at $20^{\circ} \mathrm{C}$ in the curing room.

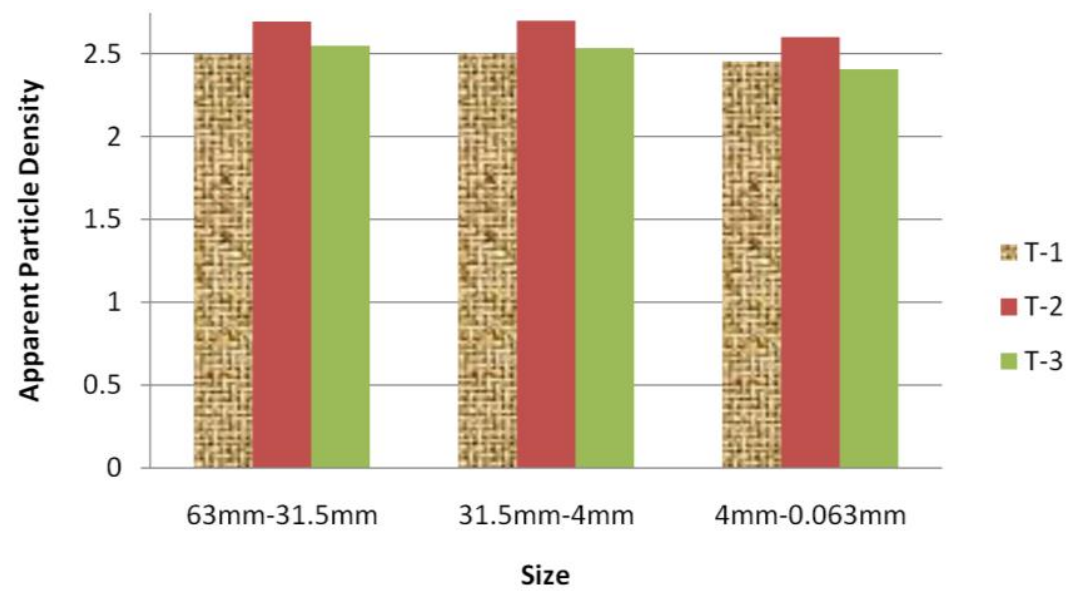

Figure 7. $\rho_{a}$ values for subbase material.

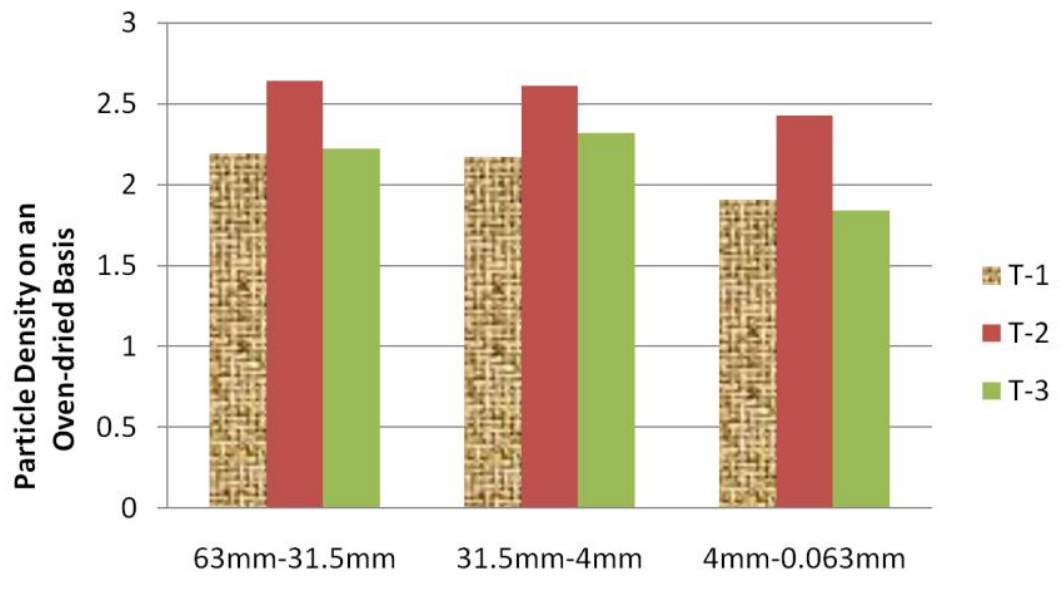

Size

Figure 8. $\rho_{r d}$ values for subbase material. 


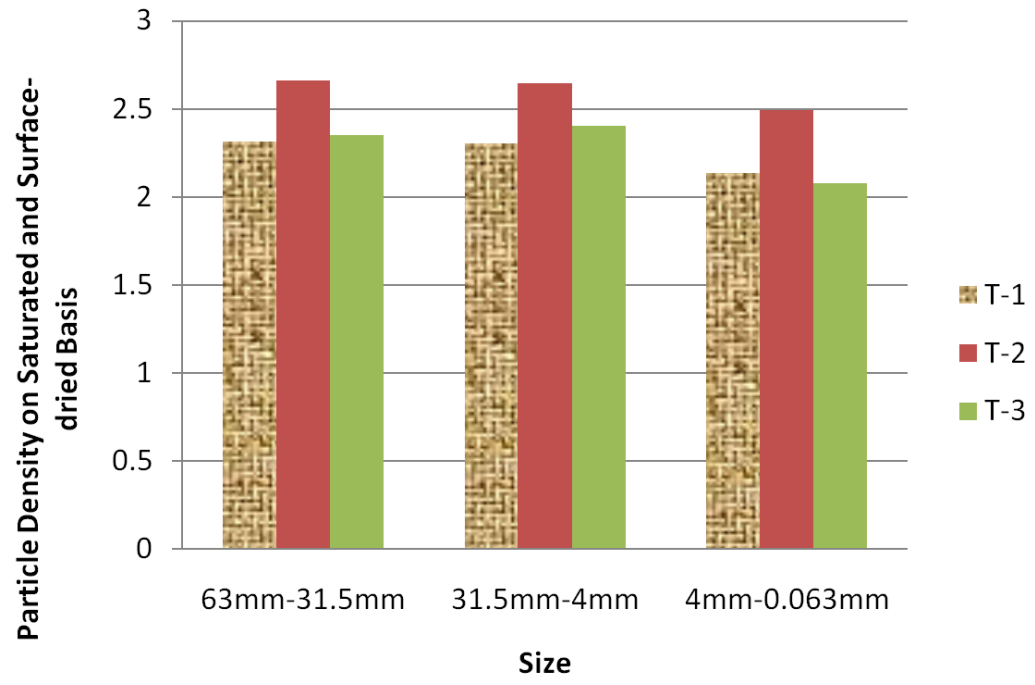

Figure 9. $\rho_{\text {ssd }}$ values for subbase material.

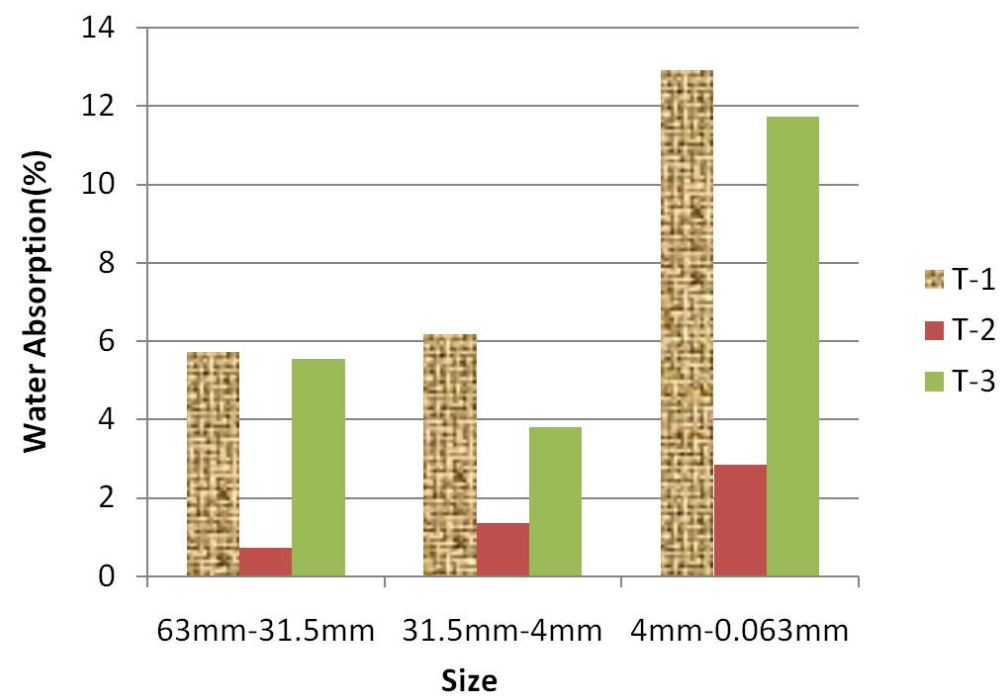

Figure 10. $W A_{24}$ values for subbase material.

$\mathrm{Mg} / \mathrm{m}^{3}$, the smaller the particle density, the higher the cement mortar content adhering to the RCA. The reason for the particle densities being lower in RCA as compared to NA is due to the relatively high porosity and low density of the cement paste adhering to the RCA particles. High porosity between the RCA particles would be filled with void or cement instead of denseportions [1].

Furthermore, particle densities of coarse aggregates are larger than those of fine aggregates, implying that a higher amount of cement mortar is attached to the fine aggregates. This behavior affects the water absorption rate of RCA in the sense that fine aggregates of RCA have a higher water absorption rate, a pattern which is consistent with the findings reported by Tam and Le (2007) [14].

In the mix of RCA and RAP (T-3), bitumen coated particles in reclaimed asphalt pavements are observed mostly in the $31.5 \mathrm{~mm}-4 \mathrm{~mm}$ particle size range. Thus the particles in the size range of $4 \mathrm{~mm}-0.063 \mathrm{~mm}$ are less coated with bitumen in T-3 and only a very s mall part is coated (Figure 11 and Figure 12). These observations make the water absorption value of T-1 about $40 \%$ higher than T-3 in $31.5 \mathrm{~mm}-4 \mathrm{~mm}$, but the water absorption of T-1 and T-3 are relatively close in the fine particles.

The particles in the size range $63 \mathrm{~mm}-31.5 \mathrm{~mm}$ of T-3 are mostly crushed concrete aggregates. This is why the water absorption and apparent particle density of coarse particles of T-3 are close to those of T-1. Figure 13 


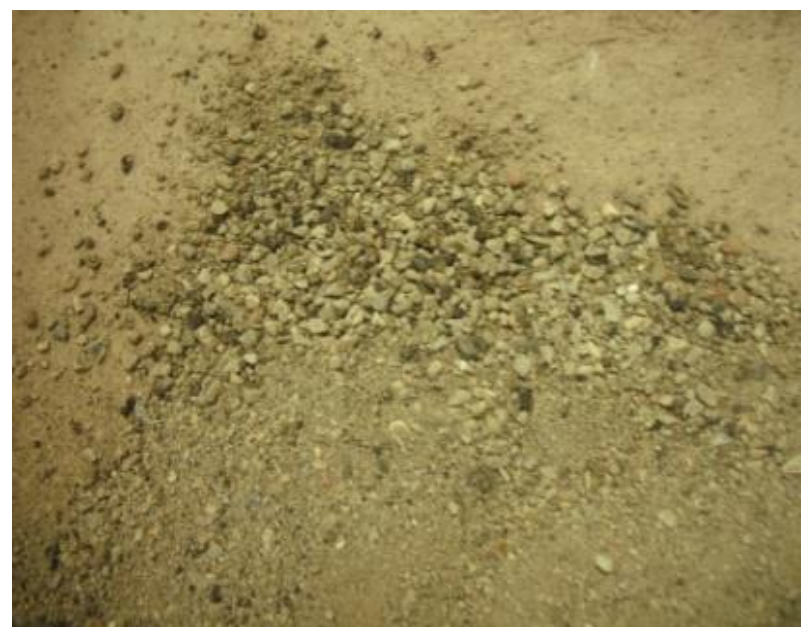

Figure 11. The fine particles of $\mathrm{T}-3$.

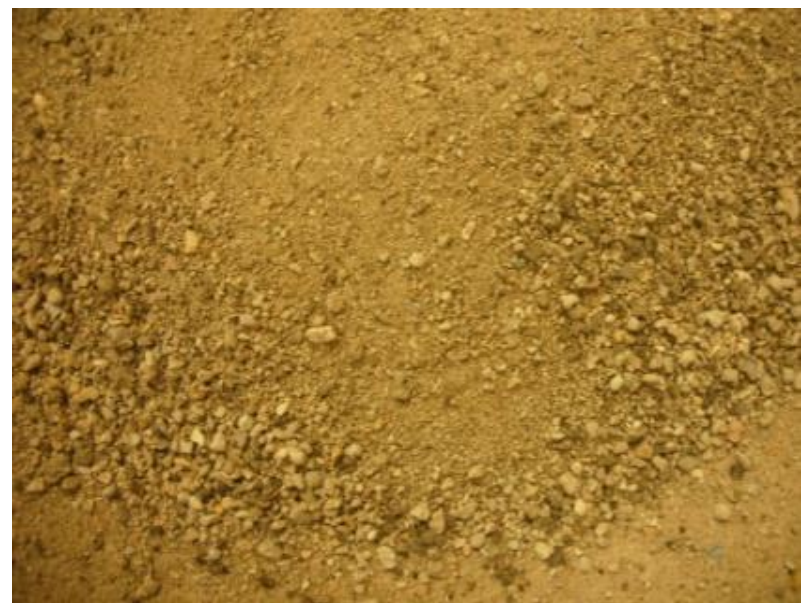

Figure 12. The fine particles of $\mathrm{T}-1$.

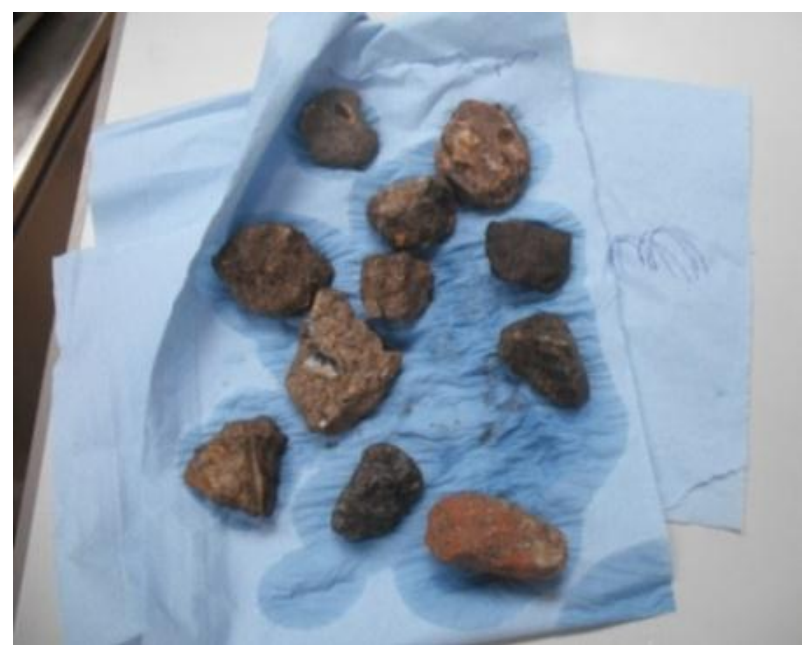

Figure 13. T-3 coarse after empting.

shows the particles after emptying the aggregates from the basket on to dry clothes and Figure 14 shows them after reaching constant mass. 


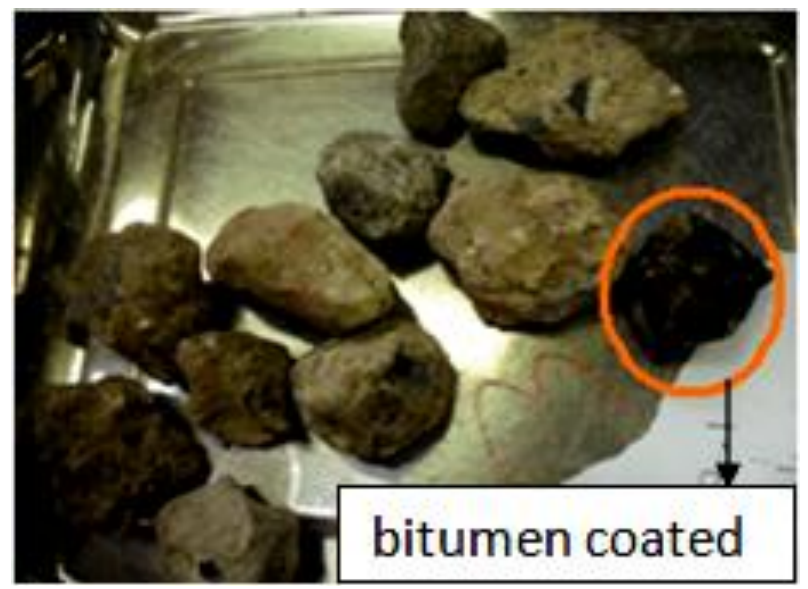

Figure 14. T-3 coarse in constant mass.

\section{Conclusions and Recommendations}

This paper presents the result of an investigation of water absorption on the use of recycled concrete and reclaimed asphalt pavement as aggregate in unbound subbase materials and then their comparison with natural aggregate behavior. Prior to the study, the mixture and grading requirement category were first evaluated. The following differences were found between the natural aggregate, recycled concrete aggregate and the mixture of recycled concrete aggregate with reclaimed asphalt pavement:

In RCA's samples, the water absorption rate of large size aggregate is less than that of small size aggregate, inferring that larger size aggregate may have less cement mortar adhered to its surface, leading to a lower water absorption rate as illustrated in the Figure 8. It is included that adhering cement mortar to material's surface will lead to higher water absorption and this is mostly valid for fine particle sized materials.

The water absorption rates of recycled aggregates (T-1 and T-3) are generally higher than that of natural aggregate. In another research by author [1] performed tests on RCA such as durability and strength tests showed that the higher water absorption can directly influence these properties. Durability test like soundness of subbase aggregates by use of sodium/magnesium sulphate and strength tests like compaction and California Bearing Ratio (CBR) are very significant require ments in construction of base and subbase layer of highways. The presence of RCA in T-1 and T-3 increased the optimu moisture content and decreased the maximum dry density as a result of the higher water absorption and the low particle density of the recycled concrete aggregates. The consequent decrease in CBR values (specially soaked CBR values) of T-1 and T-3 can be created by these factors as well. Tendency to higher water absorption increased the loss under cycles of immersion in saturated solutions of sodium sulfate followed by oven drying. Moreover, it worsened resistance against internal expansive for cederived from expansion of water on freezing.

Presence of RAP in mixes decreases water absorption properties and makes them suitable for drainage propose which is very important for unbound subbase applications.

Water absorption of RAP is $1 \%$ [5]. Adding the RCA and as a following result existing the cement in the mix T-3 increases water absorption rate by $6 \%$ in coarse particles and $120 \%$ in fine particles. In one hand, it seems that adding 50\% RAP to RCA decreases the water absorption rate and makes it suitable for subbase applications. But, on the other hand our further researches [1] showed that this replacement decreased the strength property of subbase such as CBR values. This is why, it is needed an optimum mix design of RAP and RCA both decrease the water absorption and increase strength and durability.

\section{References}

[1] Ayan, V. (2012) Assessment of Recycled Aggregates for Use in Unbound Sub-Base of Highway Pavement. Ph.D. Thesis, Kingston University London, London.

[2] Park, T. (2003) Application of Construction and Building Debris as Base and Subbase Materials in Rigid Pavement. Journal of Transportation Engineering, 129, 558-563. http://dx.doi.org/10.1061/(ASCE)0733-947X(2003)129:5(558)

[3] Poon, C.S. and Chan, D. (2006) Feasible Use of Recycled Concrete Aggregates and Crushed Clay Brick as Unbound 
Road Sub-Base. Construction and Building Materials, 20, 578-585. http://dx.doi.org/10.1016/j.conbuildmat.2005.01.045

[4] Saraf, C.L. and Majidzadeh, K. (1995) Utilization of Recycled PCC Aggregates for Use in Rigid and Flexible Pavements. Rep. FHWA-OH-95/025, Ohio Department of Transportation, Columbus.

[5] Taha, R., Al-Harthy, A., Al-Shamsi, K. and Al-Zubeidi, M. (2002) Cement Stabilization of Reclaimed Asphalt Pavement Aggregate for Road Bases and Subbases. Journal of Materials in Civil Engineering, 14, 239-245. http://dx.doi.org/10.1061/(ASCE)0899-1561(2002)14:3(239)

[6] Rodrigues, F., Evangelista, L. and Brito, J.D. (2013) A New Method to Determine the Density and Water Absorption of Fine Recy cled Aggregates. Materials Research [Online], 16, 1045-1051. http://dx.doi.org/10.1590/S1516-14392013005000074

[7] BS EN 1097-6, Tests for Mechanical and Physical Properties of Aggregates. Part 6: Determination of Particle Density and Water Absorption. British Standard Institution, London, 2000.

[8] The Highway Agency. Standards for Highways. Manual of Contract Document for Highway Works (MCHW), Volume 1, Specification for Highway Works. Series 800, Road Pavements - Unbound, Cement and Other Hydraulically Bound Mixtures, 2007.

[9] BS EN 13285, Unbound Mixtures Specification. British Standard Institution, London, 2003.

[10] The Highway Agency, Design Manual for Roads and Bridges (DMRB), Volume 7, Section 1, Part 2, HD 35/04: Conservation and the Use of Secondary and Recycled Materials, 2004.

[11] BS EN 932-1, Tests for General Properties of Aggregates, Part 1: Methods for Sampling. British Standard Institution, London, 1997.

[12] BS EN 932-2, Tests for General Properties of Aggregates, Part 2: Methods for Reducing Laboratory Samples. British Standard Institution, London, 1999.

[13] Tam, V.W.Y., Tam, C.M. and Le, K.N. (2007) Removal of Cement Mortar Remains from Recycled Aggregate Using Pre-Soaking Approaches. Resources, Conservation and Recycling, 50, 82-101. http://dx.doi.org/10.1016/j.resconrec.2006.05.012

[14] Tam, V.W.Y. and Le, K.N. (2007) Aggregate Testing Using 2nd-, 7th- and 10th-Order Interpolation Poly nomials. Resources, Conservation and Recycling, 52, 39-57. 